\title{
Laparoscopic Nissen fundoplication combined with posterior gastropexy in the surgical treatment of gastroesophageal reflux disease
}

\author{
Konstantinos E. Tsimogiannis • \\ Evangelos C. Tsimoyiannis
}

Published online: 27 February 2011

(C) Springer Science+Business Media, LLC 2011

We appreciate the comments from C. S. Davis and P. M. Fisichella regarding our recent article in Surgical Endoscopy [1]. We agree that until now, antireflux surgery, both open and laparoscopic, has been based on retrospective data and that no large randomized controlled trials have confirmed whether every technical modification improves the postoperative results or not.

The inclusion of gastropexy to prevent postoperative herniation is an old technique, and the Hill [2] posterior gastropexy is a satisfactory procedure for the treatment of gastroesophageal reflux disease (GERD). However, laparoscopic Nissen fundoplication currently is the most acceptable technique, but paraesophageal herniation has been reported as an early complication after surgery [3].

The posterior gastropexy can obtain a longer intraabdominal segment of esophagus and, in combination with cardial calibration, can restore sphincter competence [4]. The combination of laparoscopic Nissen fundoplication with posterior gastropexy described in our article gives the possibility to prevent the recurrence of the gastroesophageal reflux (Nissen fundoplication) and the avoidance of the postoperative paraesophageal herniation (posterior gastropexy) [1].

The technique of C. S. Davis and colleagues that places two stitches, one on each side of the fundoplication to pexy the fundoplication and the esophagus to the diaphragm, seems a good modification to prevent either esophagogastric intussusception or paraesophageal herniation. Before the beginning of the laparoscopic approach in our department, we had published an open modification of the Nissen

K. E. Tsimogiannis · E. C. Tsimoyiannis ( $\square)$

Department of Surgery, G. Hatzikosta General Hospital,

Hippocratus 3, Stavraki, GR-45332 Ioannina, Greece

e-mail: etsimogi@ath.forthnet.gr fundoplication to prevent the esophagogastric intussusception [5]. For this modification, after completion of the Nissen fundoplication, two more $2 / 0$ polypropylene stitches are placed between the esophageal musculature and the seromuscular layer of the gastric wrap, one on the left and the other on the right side of the esophagus. This modification, may improve the result of the Nissen fundoplication, preventing the intussusception.

This article describes a retrospective study, so the level of evidence is limited. It is well known that many modifications in the surgical treatment of the GERD have been published, but randomized controlled trials are needed to confirm their effectiveness.

Disclosures Konstantinos E. Tsimogiannis and Evangelos C. Tsimoyiannis have no conflicts of interest or financial ties to disclose.

\section{References}

1. Tsimogiannis KE, Pappas-Gogos GK, Benetatos N, Tsironis D, Farantos C, Tsimoyiannis EC (2010) Laparoscopic Nissen fundoplication combined with posterior gastropexy in surgical treatment of GERD. Surg Endosc 24:1303-1309

2. Hill LD (1977) Progress in the surgical management of hiatal hernia. World J Surg 1:425-448

3. Watson DI, deBeaux AC (2001) Complications of laparoscopic antireflux surgery. Surg Endosc 15:344-352

4. Braghetto I, Korn O, Debandi A, Burdiles P, Valladares H, Csendes A (2005) Laparoscopic cardial calibration and gastropexy for treatment of patients with reflux esophagitis: pathophysiological basis and results. World J Surg 29:636-644

5. Tsimoyiannis EC, Lekkas ET, Berekos K, Tsianos EV (1993) Modified Nissen fundoplication in the treatment of gastroesophageal reflux disease. Int Surg 78:112-116 